\title{
Dietary calcium intake in a cohort of individuals evaluated for low bone mineral density: a multicentre Italian study
}

\author{
${ }^{*}$ Elisa Cairoli1 ${ }^{1,2}$, ${ }^{*}$ Carmen Aresta ${ }^{1}$, Luca Giovanelli ${ }^{1,3}$, Cristina Eller-Vainicher ${ }^{4}$, Silvia Migliaccio ${ }^{5}$, \\ Sandro Giannini ${ }^{6}$, Andrea Giusti ${ }^{7}$, Claudio Marcocci ${ }^{8}$, Stefano Gonnelli ${ }^{9}$, Gian Carlo Isaia ${ }^{10}$, \\ Maurizio Rossini ${ }^{11} \wedge$ Iacopo Chiodini ${ }^{13}$, Marco Di Stefano ${ }^{10}$ on behalf of the Italian Society for \\ Osteoporosis, Mineral Metabolism and Skeletal Diseases (SIOMMMS)
}

*equally contributed;

${ }^{1}$ Istituto Auxologico Italiano IRCCS, Unit for Bone Metabolism Disease and Diabetes and Lab of Endocrine and Metabolic Research, Milan, Italy; e.cairoli@auxologico.it; ${ }^{2}$ Department of Pathophysiology and Transplantation, University of Milan, Milan, Italy; elisa.cairoli@auxologico.it; ${ }^{3}$ Department of Clinical Sciences and Community Health, University of Milan, Milan, Italy; iacopo.chiodini@unimi.it; ${ }^{4}$ Fondazione IRCCS Ospedale Maggiore Policlinico, Unit of Endocrinology, Milan, Italy; eller.vainicher@ gmail.com. ${ }^{5}$ Department of Movement, Human and Health Sciences, University of Rome "Foro Italico", Rome, Italy; silvia.migliaccio@uniroma4.it; ${ }^{6}$ Department of Medicine, Medical Clinic 1, University of Padua, Padua, Italy; sandro.giannini@unipd.it; ${ }^{7}$ Unit of Rheumatology, ASL3 - Liguria Region, Genoa, Italy; andrea.giusti @ galliera.it; ${ }^{8}$ Department of Clinical and Experimental Medicine, University of Pisa, Pisa, Italy; claudio.marcocci@nipi.it; ${ }^{9}$ Department of Medicine, Surgery and Neuroscience, Le Scotte University Hospital, University of Siena, Siena, Italy; stefano.gonnelli@unisi.it; ${ }^{10}$ Department of Medical Science, Section of Gerontology and Bone Metabolic Disease, University of Turin, Turin, Italy; giancarlo.isaia@ unito.it; ${ }^{11}$ Department of Medicine, Rheumatology Unit, University of Verona, Verona, Italy; maurizio.rossini@univr.it;

* Correspondence: iacopo.chiodini@unimi.it; Tel.: +3902619113496 (C.I.)

\begin{abstract}
A low calcium intake is associated with an increased fracture risk. We assessed the dietary calcium intake in a cohort of Italian individuals evaluated for low bone mineral density (BMD).

A 7-day food-frequency questionnaire was administered to 1793 individuals consecutively referred at a Centre of the Italian Society for Osteoporosis, Mineral Metabolism and Skeletal Diseases for low BMD.

In $30.3 \%(544 / 1793)$ and $20.9 \%$ (374/1793) of subjects the calcium intake was inadequate $(<700$ $\mathrm{mg} /$ day) and adequate $(>1200 \mathrm{mg} /$ day), respectively. Patients with calcium intake $<700 \mathrm{mg} /$ day showed a higher prevalence of diabetes mellitus, idiopathic hypercalciuria and food allergy/intolerance $(8.1 \%, 5.1 \%, 7.2 \%$, respectively) than patients with calcium intake $>700 \mathrm{mg} / \mathrm{day}$ $(5.3 \%, 3.0 \%, 4.1 \%$, respectively, $\mathrm{p}<0.04$ for all comparisons), also after adjusting for age, gender and BMI. In $30.3 \%$ of fractured subjects the calcium intake was $<700 \mathrm{mg} /$ day.

In Italy, a low calcium intake is highly prevalent in individuals at risk for low BMD. Importantly, an inadequate calcium intake is highly prevalent even in patients with history of fragility fractures. Only about a fifth of patients at risk for low BMD reported an adequate calcium intake.
\end{abstract}

Keywords: dietary calcium intake, osteoporosis, fractures.

\section{Introduction}

Calcium intake is a well-known factor influencing the achievement of an adequate peak bone mass [1] and, subsequently, the maintenance of bone mass later in life. Indeed, in the presence of inadequate calcium intake a negative calcium balance can develop, frequently leading to metabolic alterations, such as secondary hyperparathyroidism, increased bone turnover and, eventually, increased fracture risk [2]. 
The calcium intake largely differs among countries according to age, sex, ethnics, cultures and socioeconomic status [3] and the national recommendations on calcium intake vary worldwide. In the adult population, the Recommended Dietary Allowance (RDA) of calcium is between 1000 and $1300 \mathrm{mg} /$ day according to the US National Institutes of Health [4] and between 700 and $1000 \mathrm{mg} /$ day according to the UK National Osteoporosis Society [5]. Both the Italian Society for Osteoporosis, Mineral Metabolism and Skeletal Diseases (SIOMMMS) and the Italian Society of Human Nutrition recommends a calcium intake above $1200 \mathrm{mg}$ /day in postmenopausal women not on hormone replacement therapy and in men older than 60-65 years of age [6,7].

The adequate daily calcium requirement is influenced by several other factors, such as age, comorbidities, and vitamin D levels, the latter being fundamental for a proper intestinal calcium absorption [8]. Finally, the use of calcium supplements is still a matter of debate [9].

Despite these differences and controversies, a recent systematic review found that dietary calcium intakes fall below the recommended levels in many areas of the world [10], including Italy [11]. This is a matter of concern for bone health, especially if already threatened as in a population at risk for low bone mineral density (BMD), in whom an adequate calcium intake represents one of the first non-pharmacological interventions [6].

This is a multicenter national observational study which was aimed to assess dietary calcium intake in a cohort of Italian individuals referred for evaluation of possible low BMD.

\section{Materials and Methods}

For this cross-sectional observational study, between November 2015 and June 2016, 1793 consecutive subjects referred in one SIOMMMS referral Centre for Osteoporosis and Metabolic Bone Diseases by their General Practitioners, that agreed in participating in this study, were recruited. We excluded subjects reporting the intake of calcium supplements and/or bone active drugs because these treatments inevitably imply some kind of previous medical counselling about osteoporosis and the related importance of an adequate calcium intake and then estimated dietary calcium intake would have not reflected their usual dietary habits.

In all individuals height and weight were measured and body mass index (BMI) was calculated.

The dietary calcium intake, expressed as $\mathrm{mg} /$ day, was assessed using a specific questionnaire. In particular, usual calcium intake coming from some selected calcium-rich foods was estimated by a 7-day food frequency questionnaire derived for the International Osteoporosis Foundation (IOF) Calcium Calculator [12] after simplification according to the ordinary Italian alimentary habits. Portion sizes were quantified by means of household measures (slices, cups, glasses).

The history of clinical fragility fractures (i.e. caused by low energy trauma, such as falling from a standing height or less) was investigated at consultation. Hip and vertebral fractures (major fragility fractures) were considered apart from the others (e.g. wrist, ribs and proximal humerus). In all patients, the presence of previous fragility fractures was ascertained by self-report and no additional validation of this information was conducted.

Information about bone mineral density (BMD), measured by performed Dual-energy X-ray Absorptiometry (DXA) using reliable densitometers at lumbar spine, total femur and femoral neck and expressed as standard deviation units in relation to the young (T-score) and age-matched (Z-score) reference healthy population, were collected. DXA scans had been carried out according to the Italian Ministry of Health recommendations [13]. Diagnosis of low BMD was made in the presence of T-score at any site $\leq-2.5$ for postmenopausal women and men older than 50 [14] or in the presence of Z-score at any site $<-2.0$ for premenopausal women and men younger than 50 [15].

Demographic and clinical data were collected anonymously regarding the following comorbidities: diabetes mellitus, endogenous or iatrogenic hypercortisolism, rheumatoid arthritis (AR), idiopathic hypercalciuria, primary hyperparathyroidism (PHPT), nephrolithiasis, adverse reaction to food (including food allergy or intolerance) [16], inflammatory bowel diseases (IBD) and chronic obstructive pulmonary disease (COPD). Clinical data were confirmed by the review of medical reports. No blood or additional instrumental tests were performed. 
The protocol was approved (approval 1511/2015) by the Ethical Committee of each SIOMMMS centre and all subjects gave their written informed consent before participating in the study.

\section{Statistical Analysis}

Statistical analysis was performed by SPSS version 21.0 statistical package (SPSS Inc, Chicago, IL). In a previous study reporting the daily calcium intake in subjects with and without vertebral fracture [17] the response within each subject group was normally distributed (standard deviation 300 ) and the difference in daily calcium intake between fractured and not fractured patients was 60 $\mathrm{mg} /$ day. On the basis of these data we needed to include 329 fractured subjects and 1316 not fractured (power $90 \%$, type I error $5 \%$ ) for the study to be adequately powered.

For each continuous variables the normality of distribution was tested by the KolmogorovSmirnov test). Data were expressed as median (range) for non-normally distributed continuous variables or as mean \pm standard deviation for normally distributed variables, and as absolute and relative frequencies for categorical variables. Continuous variables were compared using one-way Student $\mathrm{t}$ test or Mann-Whitney $\mathrm{U}$ test, as appropriate. Categorical variables were compared using $\chi 2$ or Fisher's Exact test, as appropriate.

We arbitrarily decided to consider a daily calcium intake of $700 \mathrm{mg} /$ day as the threshold below which the dietary calcium intake is clearly inadequate and a supplementation is generally considered mandatory [18]. Even if some enrolled individuals were men or premenopausal women, we decided to use the threshold of $1200 \mathrm{mg} /$ day for defining an adequate calcium intake as suggested by SIOMMMS [6] in postmenopausal women not on hormone replacement therapy and in men older than 65 years of age. This decision has been taken for the sake of consistency in the data analysis since men and premenopausal females ( $\mathrm{n}=119$ and 88 , respectively) represented a minority of the entire cohort and had been however referred for low BMD and/or fragility fracture.

The multivariate logistic regression analysis was performed in order to assess the association between inadequate or adequate calcium intake (categorical dependent variable) and relevant clinical characteristics (categorical independent variables), after adjusting for possible confounders. $P$-values $<0.05$ were considered significant.

\section{Results}

The clinical characteristics of the whole cohort and the comparisons among individuals grouped according tertiles of dietary calcium intake are reported in Table 1. 


\begin{tabular}{|c|c|c|c|c|}
\hline Table 1 & $\begin{array}{c}\text { All subjects } \\
(n=1793)\end{array}$ & $\begin{array}{l}\text { I tertile } \\
(n=598)\end{array}$ & $\begin{array}{l}\text { II tertile } \\
(n=598)\end{array}$ & $\begin{array}{c}\text { III tertile } \\
(n=597)\end{array}$ \\
\hline Daily calcium intake (mg/day) & 874.9 & $<723$ & $723-1043$ & $>1043$ \\
\hline Sex (females) & $1674(93.4)$ & $567(94.8)$ & $556(93.0)$ & $551(92.3)$ \\
\hline Premenopausal females & $88(5.3)$ & $41(7.2)^{\sim}$ & $28(5.0)$ & $19(3.4)$ \\
\hline Age (years) & $\begin{array}{c}65.0 \\
(25-97)\end{array}$ & $\begin{array}{c}64.5 \\
(25-97)^{\sim}\end{array}$ & $\begin{array}{r}65.0 \\
(28-90)\end{array}$ & $\begin{array}{c}66.0 \\
(27-94)\end{array}$ \\
\hline BMI $\left(\mathrm{kg} / \mathrm{m}^{2}\right)$ & $\begin{array}{c}24.6 \\
(14.2-48.6)\end{array}$ & $\begin{array}{c}25.1 \\
(14.3-48.6) \\
\end{array}$ & $\begin{array}{c}24.2 \\
(14.2-43.9) \\
\end{array}$ & $\begin{array}{c}24.3 \\
(15.1-44.9) \\
\end{array}$ \\
\hline Low BMD & $778(43.4)$ & $253(42.3)^{\sim}$ & $242(40.5)^{\sim}$ & $283(47.3)$ \\
\hline $\begin{array}{c}\text { Prevalence of calcium intake }<700 \\
\text { mg/day }\end{array}$ & $544(30.3)$ & $544(100)$ & $0(0.0)$ & $0(0.0)$ \\
\hline $\begin{array}{c}\text { Prevalence of calcium intake }>1200 \\
\mathrm{mg} / \text { day }\end{array}$ & $374(20.9)$ & $0(0.0)$ & $0(0.0)$ & $374(100)$ \\
\hline Major fragility fractures & $368(20.5)$ & $119(19.9)^{\sim}$ & $99(16.6)^{*}$ & $150(25.1)$ \\
\hline Other fragility fractures & $334(18.6)$ & $102(17.1)$ & $119(19.9)$ & $113(18.9)$ \\
\hline $\begin{array}{l}\text { Low BMD and/or major fragility } \\
\text { fractures }\end{array}$ & $901(503)$ & $297(49.7)^{\sim}$ & $279(46.7)^{*}$ & $325(54.4)$ \\
\hline Diabetes Mellitus & $110(6.1)$ & $47(7.9)$ & $32(5.4)$ & $31(5.2)$ \\
\hline $\begin{array}{c}\text { Hypercortisolism (endogenous or } \\
\text { exogenous) }\end{array}$ & $137(7.6)$ & $44(7.3)$ & $48(8.0)$ & $45(7.5)$ \\
\hline $\mathbf{R A}$ & $269(15.0)$ & $87(14.5)$ & $93(15.6)$ & $89(14.9)$ \\
\hline Idiopathic hypercalciuria & $65(3.6)$ & $31(5.2)^{\sim}$ & $18(3.0)$ & $16(2.7)$ \\
\hline PHPT & $30(1.7)$ & $7(1.2)$ & $11(1.8)$ & $12(2.0)$ \\
\hline Nephrolitiasis & $132(7.4)$ & $47(7.9)$ & $49(8.2)$ & $36(6.0)$ \\
\hline Adverse reaction to food & $90(5.0)$ & 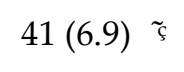 & $25(4.2)$ & $24(4.0)$ \\
\hline IBD & $65(3.6)$ & $27(4.5)$ & $16(2.7)$ & $22(3.7)$ \\
\hline COPD & $71(4.0)$ & $22(3.7)$ & $24(4.0)$ & $25(4.2)$ \\
\hline
\end{tabular}

Data are expressed as median values (range) or absolute number (percentage).; ${ }^{*} \mathrm{p}<0.005$ vs tertile III; $\tilde{\mathrm{p}}<0.05$ vs tertile III; $` \mathrm{p}<0.05$ vs tertile II. BMI: body mass index. RA: rheumatoid arthritis. PHPT: primary hyperparathyroidism. IBD: inflammatory bowel disease. COPD: chronic obstructive pulmonary disease. Low BMD: T-score at any site $\leq-2.5$ for postmenopausal women and men older than 50 or in the presence of Z-score at any site $<-2.0$ for premenopausal women and men $<50$ years. 
In the entire cohort the mean calcium intake was $874.9 \mathrm{mg} /$ day, The $30.3 \%$ of the enrolled subjects showed a clearly inadequate calcium intake and in only $20.9 \%$ of subjects the calcium intake was adequate (Figure 1).

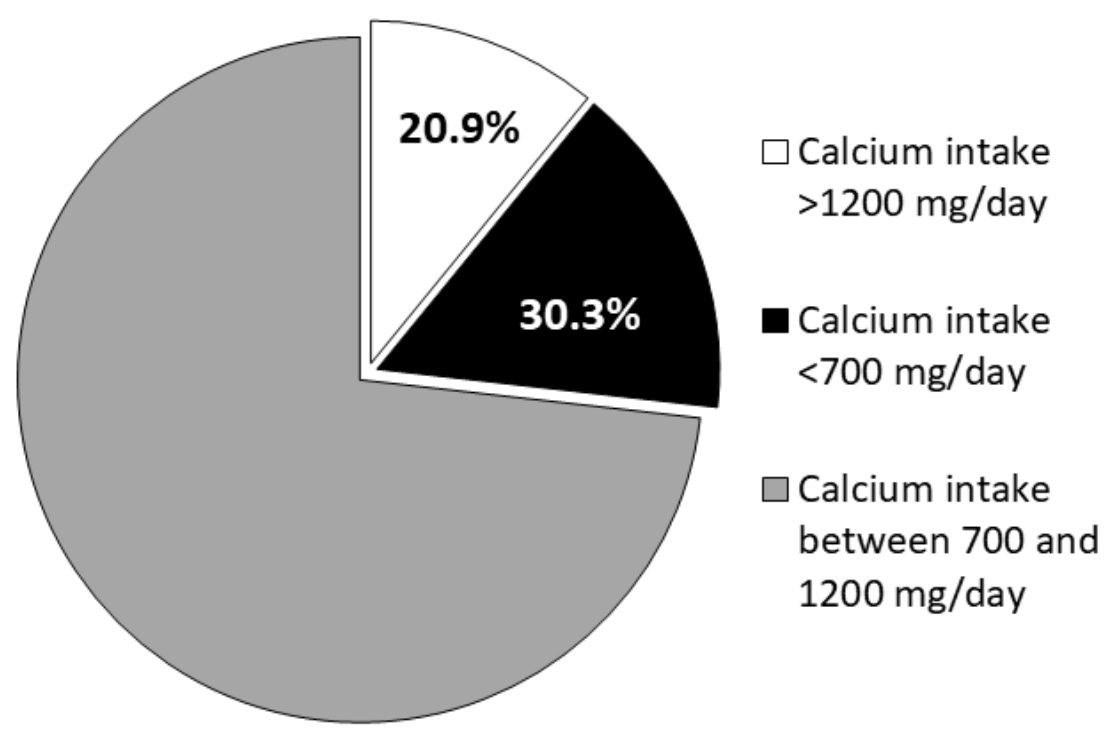

Figure 1. Prevalence of adequate, intermediate and definitely inadequate dietary dietary calcium intake (>1200 mg/day, 700-1200 mg/day and <700 mg/day, respectively), in 1793 individuals referred to outpatients clinics for osteoporosis of the Italian Society for Osteoporosis, Mineral Metabolism and Skeletal Diseases

Three hundred sixty-eight subjects reported a previous major fragility fracture, whereas the remaining $1425 \mathrm{did}$ not, thus respecting the sample size calculation requested to guarantee the adequate power of the study. The enrolled subjects were mainly females and were comparable among the different tertiles as far as gender, BMI and prevalence of the main comorbidities. Subjects in the lowest and intermediate tertiles were younger and showed a lower prevalence of low BMD and major fragility fractures than those in the highest tertile. Moreover, the prevalence of premenopausal females, idiopathic hypercalciuria and adverse reaction to food was higher in subjects in the lowest tertile than in those in the highest tertile of daily dietary calcium intake.

The Table 2 illustrates the comparisons between subjects with calcium intake below and above $700 \mathrm{mg} /$ day. The patients with calcium intake $<700 \mathrm{mg} /$ day showed an increased prevalence of idiopathic hypercalciuria, diabetes mellitus and of a personal history of adverse reaction to food compared to patients with calcium intake $>700 \mathrm{mg} /$ day. Age, BMI, prevalence of low BMD, fragility fractures and other comorbidities (RA, endogenous or exogenous hypercortisolism, PHPT, nephrolithiasis, IBD and COPD) were comparable between the two groups. 


\begin{tabular}{|c|c|c|c|}
\hline Table 2 & $\begin{array}{l}\text { Calcium intake } \\
<700 \mathrm{mg} / \text { day } \\
(\mathrm{n}=544)\end{array}$ & $\begin{array}{l}\text { Calcium intake } \\
>700 \mathrm{mg} / \text { day } \\
(\mathrm{n}=1249)\end{array}$ & $p$ \\
\hline Sex (females) & $517(95)$ & $1157(92.6)$ & 0.060 \\
\hline Age (years) & $65(25-97)$ & $65(27-94)$ & 0.170 \\
\hline BMI $\left(\mathrm{kg} / \mathrm{m}^{2}\right)$ & $25.0(17.3-48.6)$ & $24.4(14.2-44.9)$ & 0.190 \\
\hline Low BMD osteoporosis & $236(43.4)$ & $542(43.4)$ & 0.990 \\
\hline Major fragility fractures & $113(20.8)$ & $255(20.4)$ & 0.860 \\
\hline Other fragility fractures & $92(16.9)$ & $242(19.4)$ & 0.220 \\
\hline $\begin{array}{l}\text { Low BMD and/or major fragility } \\
\text { fractures }\end{array}$ & $274(50.4)$ & $627(50.2)$ & 0.948 \\
\hline Diabetes Mellitus & $44(8.1)$ & $66(5.3)$ & 0.020 \\
\hline $\begin{array}{l}\text { Hypercortisolism (endogenous or } \\
\text { exogenous) }\end{array}$ & $40(7.4)$ & $97(7.7)$ & 0.720 \\
\hline RA & $76(14.0)$ & $193(15.5)$ & 0.420 \\
\hline Idiopathic hypercalciuria & $28(5.1)$ & $37(3.0)$ & 0.020 \\
\hline PHPT & $6(1.1)$ & $24(1.9)$ & 0.210 \\
\hline Nephrolithiasis & $45(8.3)$ & $87(7.0)$ & 0.330 \\
\hline Adverse reaction to food & $39(7.2)$ & $51(4.1)$ & 0.006 \\
\hline IBD & $24(4.4)$ & $41(3.3)$ & 0.240 \\
\hline COPD & $19(3.5)$ & $52(4.2)$ & 0.500 \\
\hline \multicolumn{4}{|c|}{$\begin{array}{l}\text { Data are expressed as median values (range) or absolute number (percentage). BMI: body mass } \\
\text { index; RA: rheumatoid arthritis; PHPT: primary hyperparathyroidism; IBD: inflammatory bowel } \\
\text { disease; COPD: chronic obstructive pulmonary disease. BMD: Bone mineral density. Low BMD: } \\
\text { T-score at any site } \leq-2.5 \text { for postmenopausal women and men older than } 50 \text { or in the presence of } \\
\text { Z-score at any site }<-2.0 \text { for premenopausal women and men younger than } 50 \text {. }\end{array}$} \\
\hline
\end{tabular}

Interestingly, about one third of subjects with low BMD (236/778) and one third of subjects with fragility fractures (113/368) had a calcium intake below $700 \mathrm{mg} /$ day (Figure 2). 


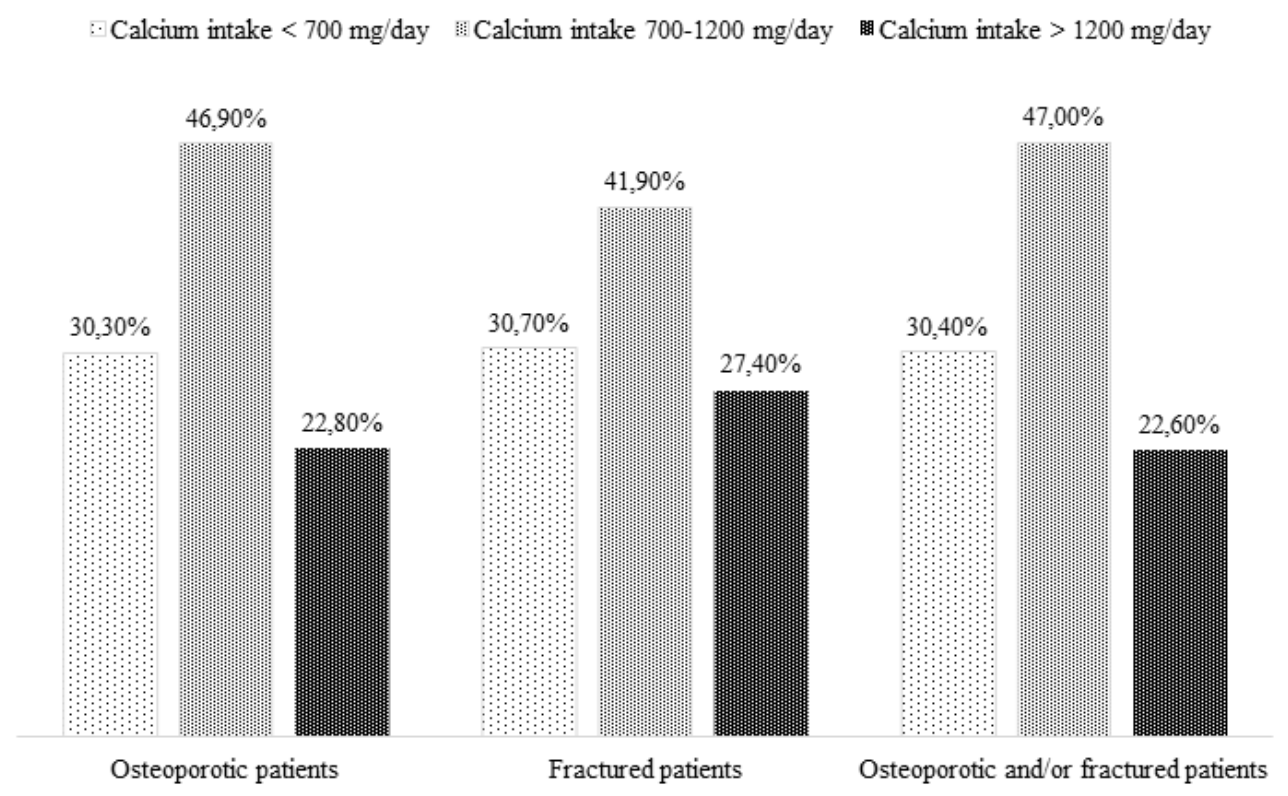

Figure 2: Prevalence of adequate, intermediate and definitely inadequate dietary dietary calcium intake (>1200 mg/day, 700-1200 mg/day and $<700 \mathrm{mg} /$ day, respectively), in 1793 individuals referred to outpatients clinics for osteoporosis of the Italian Society for Osteoporosis, Mineral Metabolism and Skeletal Diseases stratified on the basis of the presence of densitometric low bone mineral density (BMD) or fragility fractures or both

The Logistic regression analysis showed that a calcium intake below $700 \mathrm{mg} /$ day was independently associated with the female gender (odds ratio [OR]: 1.58; 95\% confidence interval [CI]: 1.01-2.47; $\mathrm{p}=0.047$ ), a history of diabetes mellitus (OR: 1.61; 95\%CI: 1.07-2.42; $\mathrm{p}=0.023$ ), food intolerance/allergy (OR: 1.82; 95\%CI: 1.18-2.82; $\mathrm{p}=0.007$ ) or a previous diagnosis of idiopathic hypercalciuria (OR: 1.73; 95\%CI: 1.04-2.89; $\mathrm{p}=0.035$ ), regardless of age, $\mathrm{BMI}$, the presence of low BMD and of major fragility fractures.

The comparison between individuals with calcium intake below or above $1200 \mathrm{mg} / \mathrm{die}$ is depicted in Table 3.

\begin{tabular}{|c|c|c|c|}
\hline Table 3 & $\begin{array}{l}\text { Calcium intake } \\
<1200 \mathrm{mg} / \text { day } \\
(\mathrm{n}=1419)\end{array}$ & $\begin{array}{l}\text { Calcium intake } \\
>1200 \mathrm{mg} / \text { day } \\
(\mathrm{n}=374)\end{array}$ & $p$ \\
\hline Sex (females) & $1329(93.7)$ & $345(92.2)$ & 0.330 \\
\hline Age (years) & $65(25-97)$ & $65(37-94)$ & 0.073 \\
\hline BMI $\left(\mathrm{kg} / \mathrm{m}^{2}\right)$ & $24.7(14.2-48.6)$ & $24.2(15.1-38.0)$ & 0.063 \\
\hline Low BMD & $601(42.4)$ & 177 (47.3) & 0.080 \\
\hline Major fragility fractures & $267(18.8)$ & $101(27.0)$ & 0.001 \\
\hline Other fragility fractures & $268(18.9)$ & $66(17.6)$ & 0.580 \\
\hline
\end{tabular}




\begin{tabular}{|c|c|c|c|}
\hline $\begin{array}{l}\text { Low BMD and/or major fragility } \\
\text { fractures }\end{array}$ & $697(49.1)$ & $204(54.5)$ & 0.062 \\
\hline Diabetes Mellitus & $94(6.6)$ & $16(4.3)$ & 0.090 \\
\hline $\begin{array}{l}\text { Hypercortisolism (endogenous or } \\
\text { exogenous) }\end{array}$ & $105(7.4)$ & $32(8.6)$ & 0.520 \\
\hline RA & $219(15.4)$ & $50(13.4)$ & 0.320 \\
\hline Idiopathic hypercalciuria & $53(3.7)$ & $12(3.2)$ & 0.630 \\
\hline PHPT & $19(1.3)$ & $11(2.9)$ & 0.032 \\
\hline Nephrolithiasis & $114(8.0)$ & $18(4.8)$ & 0.034 \\
\hline Adverse reaction to food & $78(5.5)$ & $12(3.2)$ & 0.070 \\
\hline IBD & $56(3.9 \%)$ & $9(2.4)$ & 0.160 \\
\hline COPD & $54(3.8)$ & $17(4.5)$ & 0.510 \\
\hline \multicolumn{4}{|c|}{$\begin{array}{l}\text { Data are expressed as median values (range) or absolute number (percentage). } \\
\text { BMI: body mass index. RA: rheumatoid arthritis. PHPT: primary hyperparathyroidism. IBD: } \\
\text { inflammatory bowel disease. COPD: chronic obstructive pulmonary disease. BMD: bone mineral } \\
\text { density. Low BMD: T-score at any site } \leq-2.5 \text { for postmenopausal women and men older than } 50 \text { or } \\
\text { in the presence of Z-score at any site }<-2.0 \text { for premenopausal women and men younger than } 50 \text {. }\end{array}$} \\
\hline
\end{tabular}

Patients with calcium intake above $1200 \mathrm{mg} /$ day showed a lower prevalence of nephrolithiasis, but a higher prevalence of major fragility fractures and of history of previous PHPT compared to the patients with calcium intake below $1200 \mathrm{mg} /$ day. Age, gender, BMI and prevalence of prior evidence of low BMD and other assessed comorbidities (RA, endogenous or exogenous hypercortisolism, IBD, food intolerance/allergy, COPD and diabetes) were comparable between the two groups. It is worth underlying that only $23 \%$ and $27 \%$ of low BMD and fractured subjects, respectively, had an adequate daily calcium intake (Figure 2 ). An adequate calcium intake was inversely associated with BMI (OR: 1.04; 95\%CI: 1.01-1.06; $\mathrm{p}=0.016$ ) and directly associated with a history of major fragility fractures (OR: 1.55; 95\%CI: 1.16-2.07; $\mathrm{p}=0.003$ ), a previous diagnosis of PHPT (OR: 2.66; 95\%CI: 1.23-5.75; $\mathrm{p}=0.013$ ) and the absence of nephrolithiasis (OR: 1.86; 95\%CI: 1.10-3.14; $\mathrm{p}=0.020$ ), regardless of age, gender and the presence of low BMD.

Individuals with low BMD and/or fractures showed a higher calcium intake (949.9 \pm 417.3 $\mathrm{mg} /$ day), were older $(67.7 \pm 10.3$ years) and less frequently premenopausal $(1.9 \%)$ than those without low BMD and fractures $(907.5 \pm 382.9 \mathrm{mg} /$ day, $\mathrm{p}=0.025 ; 61.3 \pm 10.8$ years, $\mathrm{p}<0.0001 ; 8.7 \%, \mathrm{p}<0.0001$, respectively). The logistic regression analysis showed that the presence of low BMD and/or fragility fractures was not associated with the daily calcium intake.

Finally, even excluding male patients and premenopausal females from the analyses, the results did not change (data not shown).

\section{Discussion}

The present study shows that the mean calcium intake in a cohort of Italian individuals referred for the evaluation of low BMD is lower than recommended. Recommended daily calcium intake in the general adult population varies across countries and according to the different guidelines. 
However, a daily calcium intake of at least $1000-1200 \mathrm{mg} /$ day is usually considered adequate $[4,6,7,19]$. A quite recent systematic review shows that mean dietary calcium intakes fall below the recommended levels in many areas of the world [10], including Italy, where a survey on this topic performed in 2005-2006 reveals an average calcium intake in the adult population of $765 \mathrm{mg} /$ day [11]. The mean daily calcium intake in the present study (about $875 \mathrm{mg}$ ) is better than before, but still insufficient, especially considering that these data were collected in a population at risk of low BMD. Indeed, it is well-established that an adequate calcium and vitamin D intake is essential for bone health and that a low calcium intake is associated with an increased fracture risk [20]. Our results are in agreement with those of previous studies showing a mean calcium intake lower than the recommended thresholds in osteoporotic populations, both in Europe [21] and in Italy [22].

It is worth noting that within our cohort almost one third of individuals with low BMD and/or fractures had an estimated calcium intake lower than $700 \mathrm{mg} /$ day, the threshold below which the dietary calcium intake is considered to be associated with an increased risk of fracture and osteoporosis and below which a supplementation is considered mandatory [18] and less than a quarter of individuals with low BMD and/or fractures had an adequate daily calcium intake. Despite these findings, indicating an insufficient awareness of the importance of this nutritional issue for bone health, the prevalence of low BMD and previous major fragility fractures were higher in subjects of the third tertile than in those of the first and second tertiles of daily dietary calcium intake. This finding might be explained by the possibility that individuals with low BMD and/or fractures are more prone to increase the daily calcium intake. In keeping, individuals with low BMD and/or fractures were older than those without low BMD and/or fractures and the dietary calcium intake increased with age. Accordingly, premenopausal females were more represented in the lowest tertile of daily calcium intake. Therefore, even if entirely speculative, this may suggest that the awareness of a low BMD and/or of a fragility fracture could have positively influenced the nutritional habits.

Moreover, individuals in the lowest tertile of daily calcium intake showed a higher prevalence of idiopathic hypercalciuria and of adverse food reactions (mainly lactose intolerance, to a lesser extent food allergy or autoimmune intollerance) than patients in the highest tertile. This result was also confirmed when we compared patients with calcium intake below and above $700 \mathrm{mg} /$ day and, in particular, these conditions were associated with an inadequate calcium intake independent of possible confounders, including the presence of low BMD and prevalent fragility fractures. These findings suggest that adverse food reactions and the presence of hypercalciuria may have contributed to decrease calcium intake. Indeed, despite the availability of lactose-reduced or lactose-free dairy products, lactose-intolerant individuals frequently avoid milk and derivatives which represent the main sources of dietary calcium and so are at risk of calcium inadequacy [23]. Likewise, hypercalciuric subjects, possibly not appropriately informed, could have been worried of worsening the urinary calcium excretion by assuming dairy products. Conversely, it is known that an adequate dietary calcium intake is important even in hypercalciuric individuals in order to counterbalance the increased urinary loss and avoid a negative calcium balance [24].

An inadequate calcium intake was also independently associated with the female gender and with the presence of diabetes mellitus. The first result, despite being consistent with previous data [10], acquires even more value considering that calcium requirements in women are generally higher than in men of the same age [19]. A history of diabetes mellitus could have negatively influenced calcium intake due to the need to follow not only a hypoglucidic but also a cholesterol-lowering diet, which is a known factor risk for reduced calcium intake and low BMD [25].

The comparison between patients with calcium intake below and above $1200 \mathrm{mg} /$ day showed that an adequate daily calcium intake was associated with a lower prevalence of nephrolithiasis, and a higher history of major fragility fractures and a previous diagnosis of PHPT. The lower rate of nephrolithiasis in patients with adequate calcium intake is in keeping with the amount of data about the protective role against the lithogenic risk of the normocalcic diet [26]. In our opinion, the apparently unexpected findings of a higher history of major fragility fractures and a previous diagnosis of PHPT in subjects with adequate daily calcium intake have plausible explanations. 
Indeed, as discussed above, a previous fragility fracture may have encouraged subjects to increase their daily calcium intake. Similarly, a past diagnosis of PHPT and the subsequent transient hypocalcemia may have contributed to increase the awareness of the importance of an adequate calcium intake.

Anyway, even though fractured patients have more likely an adequate calcium intake as compared to the not fractured ones, the proportion of fractured subjects with an adequate calcium intake does not exceed the $28 \%$, thus indicating that over two-thirds of fractured patients had an inadequate calcium intake. Finally, the fact that hypercortisolism was not associated with a higher prevalence of adequate calcium intake confirms the still insufficient awareness in Italy of the importance of and adequate calcium intake for maintaining the skeletal health [27].

The current study has several limitations. Firstly, the cross-sectional design permits to find associations but not to demonstrate a link of causality. Indeed, the recruitment of patients in referral centres for osteoporosis can have introduced a selection bias. Indeed, in some individuals the calcium intake assessed in this study reflects the individual habits before the diagnosis of osteoporosis and/or the occurrence of a fragility fracture. However, many subjects have probably been referred to these centres after the diagnosis of osteoporosis was made by their General Practitioners. Thus, it is not possible to discriminate whether these data reflect the attitude of the Italian General Practitioners in suggesting an adequate calcium intake in patients with at risk for fractures or the individual dietary habits. Secondly, the questionnaire assessed the dietary calcium intake at the moment of the study enrolment, and, therefore, could not have been informative of the dietary calcium intake in the past. Finally, a limitation of the study is the lack of data on vitamin D status in our sample which could have been useful in the interpretation of the results.

Overall, despite these limitations, our data suggest that, to date, an inadequate calcium intake is still highly prevalent in a population with low BMD or at risk for this condition. Educational campaigns should be encouraged to correct the lack of knowledge about the safety and the benefits of an adequate calcium intake and, conversely, about the risks associated with a low calcium intake, particularly in osteoporotic or already fractured subjects

Author Contributions: Conceptualization I.C., C.E-V., S.M., S.G., C.M., S.G., GC. I, M.DS.; Methodology, I.C., C.E-V., S.M., S.G., C.M., GC.I., M.DS; Software, I.C, M.DS.; Validation M.R., I.C., A.G.; Formal Analysis, I.C., C.A., L.G., C.E-V.; Investigation, C.A., L.G., C.E-V., A.G.; Resources, M.A., C.M., S.G.; Data Curation, C.A., L.G., C.E-V. A.G.; Writing - Original Draft Preparation, I.C., E-V.C., M.DS; Writing - Review \& Editing, M.R, C.M., S.G., A.G.; Visualization, M.R., C.M., S.G., GC.I.; Supervision, M.R.; Project Administration, M.R.

Funding: This research received no external funding

Acknowledgments: the following SIOMMMS colleagues actively participated in the subjects' recruitment:

1. Valter Galmarini, Unit of Orthopedic and Traumatology, Ospedale Fatebenefratelli-Sacco, Milan

2. Giovanni Passeri, Department of Clinical and Experimental Medicine, Center for Metabolic Bone Diseases, University of Parma

3. Fabio Di Salvo, Sanicam Palermo

4. Giangiacomo Osella, Medina Interna, AOU San Luigi Gonzaga, Orbassano, Turin

5. Francesco Tripodi, Center for the Prevention, Diagnosis and Cure of Osteoporosis and Osteoarticular Disorders, Ospedale Fucito di Mercato Ss. A.O.U.Salerno

6. Roberto Valenti, Center for Metabolic Bone Diseases, Unit of Internal Medicine - AOU Senese "S. Maria alle Scotte", Siena

7. Gloria Bonaccorsi, Department of Morphology, Surgery and Experimental Medicine, University of Ferrara

8. Gilberta Giacchetti, Endocrinology Clinic- Azienda Ospedaliero-Universitaria Ospedali Riuniti Ancona

9. Flavia Pugliese, Unit of Endocrinology, Casa Sollievo della Sofferenza, San Giovanni Rotondo, Foggia

10. Andrea Casabella. Dept of Internal Medicine and Medical Specialties, Policlinico San Martino, Genova 
11. Bruno Seriolo, Rheumatology, University of Genova

12. Antonio Giovanni Emilio Masala and Pileri Piera Veronica, Istituto Patologia Medica AOU Sassari

13. Letizia Maninetti, Unit of Internal Medicine, ASST-Cremona

14. Alessio De Santis, Casa di Cura Villa Serena, Catanzaro

15. Alfredo Bardoscia, IRCCS Bari

16. Alice Parma, Rheumatology, University of Pisa

17. Paolo Caso and Monica Mazza, University of Rome.

Conflicts of Interest: The authors declare no conflict of interest

\section{References}

1. Weaver CM, Gordon CM, Janz KF, Kalkwarf HJ, Lappe JM, Lewis R, O'Karma M, Wallace TC, Zemel BS (2016) The National Osteoporosis Foundation's position statement on peak bone mass development and lifestyle factors: a systematic review and implementation recommendations. Osteoporos Int 27(4):1281-1386. doi:10.1007/s00198-015-3440-3.

2. Mirza F, Canalis E (2015) Management of endocrine disease: Secondary osteoporosis: pathophysiology and management. Eur J Endocrinol 173(3):R131-51. doi:10.1530/EJE-15-0118.

3. Burckhardt P (2013) Calcium revisited: part I. Bonekey Rep 2:433. doi:10.1038/bonekey.2013.167.

4. National Institutes of Health. Calcium - Fact Sheet for Health Professionals. https://ods.od.nih.gov/factsheets/Calcium-HealthProfessional/ Accessed 07/02/2020.

5. Royal Osteoporosis Cociety. Calcium. https://theros.org.uk/information-and-support/looking-after-your-bones/nutrition-for-bones/calcium/) Accessed 07/02/2020.

6. Rossini M, Adami S, Bertoldo F, Diacinti D, Gatti D, Giannini S, Giusti A, Malavolta N, Minisola S, Osella G, Pedrazzoni M, Sinigaglia L, Viapiana O, Isaia GC (2016) Guidelines for the diagnosis, prevention and management of osteoporosis. Reumatismo 68(1):1-39. doi: 10.4081/reumatismo.2016.870.

7. Società Italiana di Nutrizione Umana-SINU (2014) LARN - Livelli di assunzione di riferimento per la popolazione italiana: MINERALI. https://sinu.it/2019/07/09/minerali-assunzione-raccomandata-per-la-popolazione-pri-e-assunzione-adegua taai/) Accessed 07/02/2020.

8. Heaney RP (2008) Vitamin D and calcium interactions: functional outcomes. Am J Clin Nutr 88(2):541S-544S.

9. Chiodini I, Bolland MJ (2018) Calcium supplementation in osteoporosis: useful or harmful? Eur J Endocrinol 178(4):D13-D25. doi: 10.1530/EJE-18-0113.

10. Balk EM, Adam GP, Langberg VN, Earley A, Clark P, Ebeling PR, Mithal A, Rizzoli R, Zerbini CAF, Pierroz DD, Dawson-Hughes B (2017) International Osteoporosis Foundation Calcium Steering Committee. Global dietary calcium intake among adults: a systematic review. Osteoporos Int 28(12):3315-3324. doi:10.1007/s00198-017-4230-x.

11. Sette S, Le Donne C, Piccinelli R, Arcella D, Turrini A, Leclercq C (2011) INRAN-SCAI 2005-6 Study Group. The third Italian National Food Consumption Survey, INRAN-SCAI 2005-06--part 1: nutrient intakes in Italy. Nutr Metab Cardiovasc Dis 21(12):922-32. doi: 10.1016/j.numecd.2010.03.001.

12. International Osteoporosis Foundation (IOF) Calcium Calculator. https://www.iofbonehealth.org/calcium-calculator. Accessed 07/02/2020.

13. Gazzetta Ufficiale Serie Generale n.104 del 07-05-2007 - Allegato 2Bb. Fattori di rischio per l'erogazione delle prestazioni di densitometria ossea. https:/www.gazzettaufficiale.it/eli/gu/2007/05/07/104/sg/pdf. Accessed 20/03/2020.

14. Kanis JA (1994) Assessment of fracture risk and its application to screening for postmenopausal osteoporosis: synopsis of a WHO report. WHO Study Group. Osteoporos Int 4(6):368-81.

15. Baim S, Binkley N, Bilezikian JP, Kendler DL, Hans DB, Lewiecki EM, Silverman S (2008) Official Positions of the International Society for Clinical Densitometry and executive summary of the 2007 ISCD Position Development Conference. J Clin Densitom 11(1):75-91. doi: 10.1016/j.jocd.2007.12.007. 
16. EFSA NDA Panel (EFSA Panel on Dietetic Products, Nutrition and Allergies) (2014) Scientific Opinion on the evaluation of allergenic foods and food ingredients for labelling purposes. EFSA Journal 12(11):3894, 286 pp. doi:10.2903/j.efsa.2014.3894

17. Eller-Vainicher C, Chiodini I, Santi I, Massarotti M, Pietrogrande L, Cairoli E, Beck-Peccoz P, Longhi M, Galmarini V, Gandolini G, Bevilacqua M, Grossi E (2011) Recognition of morphometric vertebral fractures by artificial neural networks: analysis from GISMO Lombardia Database. PLoS One 6(11):e27277. doi: 10.1371/journal.pone.0027277.

18. Warensjö E, Byberg L, Melhus H, Gedeborg R, Mallmin H, Wolk A, Michaëlsson K (2011) Dietary calcium intake and risk of fracture and osteoporosis: prospective longitudinal cohort study. BMJ 342:d1473. doi: 10.1136/bmj.d1473.

19. IOM (Institute of Medicine) (2011). Dietary Reference Intakes for Calcium and Vitamin D. Washington, DC: The National Academies Press.

20. Weaver CM, Alexander DD, Boushey CJ, Dawson-Hughes B, Lappe JM, LeBoff MS, Liu S, Looker AC, Wallace TC, Wang DD (2016) Calcium plus vitamin D supplementation and risk of fractures: an updated meta-analysis from the National Osteoporosis Foundation. Osteoporos Int 27(1):367-76. doi: 10.1007/s00198-015-3386-5. Erratum in: Osteoporos Int. 2016 Aug;27(8):2643-6.

21. Bruyere O, De Cock C, Mottet C, Neuprez A, Malaise O, Reginster JY (2009) Low dietary calcium in European postmenopausal osteoporotic women. Public Health Nutr 12(1):111-4. doi: 10.1017/S1368980008002024.

22. Adami S, Giannini S, Giorgino R, Isaia G, Maggi S, Sinigaglia L, Filipponi P, Crepaldi G, Di Munno O (2003) The effect of age, weight, and lifestyle factors on calcaneal quantitative ultrasound: the ESOPO study. Osteoporos Int 14(3):198-207.

23. Suchy FJ, Brannon PM, Carpenter TO, Fernandez JR, Gilsanz V, Gould JB, Hall K, Hui SL, Lupton J, Mennella J, Miller NJ, Osganian SK, Sellmeyer DE, Wolf MA (2010) NIH Consensus Development Conference Statement: Lactose Intolerance and Health. NIH Consens State Sci Statements 27(2):1-27.

24. Escribano J, Balaguer A, Roqué i Figuls M, Feliu A, Ferre N (2014) Dietary interventions for preventing complications in idiopathic hypercalciuria. Cochrane Database Syst Rev 2:CD006022. doi: 10.1002/14651858.CD006022.pub4.

25. Varenna M, Binelli L, Zucchi F, Ghiringhelli D, Sinigaglia L (2001) Unbalanced diet to lower serum cholesterol level is a risk factor for postmenopausal osteoporosis and distal forearm fracture. Osteoporos Int 12(4):296-301.

26. Prezioso D, Strazzullo P, Lotti T, Bianchi G, Borghi L, Caione P, Carini M, Caudarella R, Ferraro M, Gambaro G, Gelosa M, Guttilla A, Illiano E, Martino M, Meschi T, Messa P, Miano R, Napodano G, Nouvenne A, Rendina D, Rocco F, Rosa M, Sanseverino R, Salerno A, Spatafora S, Tasca A, Ticinesi A, Travaglini F, Trinchieri A, Vespasiani G, Zattoni F; CLU Working Group (2015) Dietary treatment of urinary risk factors for renal stone formation. A review of CLU Working Group. Arch Ital Urol Androl 87(2):105-20. doi: 10.4081/aiua.2015.2.105. Erratum in: Arch Ital Urol Androl. 2016 Mar;88(1):76.

27. Manolagas SC, Weinstein RS (1999) New developments in the pathogenesis and treatment of steroid-induced osteoporosis. J Bone Miner Res 14(7):1061-6. 